\title{
IUFOST2006/990 \\ Multiscale simulation with Lattice Boltzmann of natural and forced convection in stored or packed agricultural produce
}

\author{
R. Van Der Sman \\ Wageningen University, P.O. Box 8129, 6700 Wageningen, Netherlands \\ ruud.vandersman@wur.nl
}

The last decade the Lattice Boltzmann method has evolved into a powerfull solver for flow through porous media, where the solid phase is represented fully resolved on the computational grid (Hill, 2001). Packed and stored fresh agricultural produce are frequently modeled as porous media - and therefore we envision Lattice Boltzmann to be an important tool for simulating heat and mass transport in these systems via forced or natural convection. However, practical package and storage systems have too large lengthscales for fully resolved simulations. Consequently, simulations on the full system scale have to be performed at the volume-averaged scale. For the volume-averaged scale closure relations are needed such as the drag force, effective diffusivity or conductivity. Also here Lattice Boltzmann can play a vital role. Lattice Boltzmann is also capable of simulations at the volume-averaged scale, though it has not frequently used for this scale. With this capability, we can build a multiscale simulation approach, similar to what is developed for fluidized beds (van der Hoef, 2004).

In this contribution we will present the general framework, and applications of Lattice Boltzmann to forced flow through package with spherical produce (fully resolved), natural convection in bulk containers of seed potatoes (volume-averaged) (van der Sman,1997 \& 1999), and some benchmark problems like natural convection in cavity (van der Sman, 2006) and flow in a channel with a porous layer (Beavers and Joseph benchmark).

References o Hill R.J., Koch D.L., and Ladd A.J.C. Moderate-Reynolds-number flows in ordered and random arrays of spheres JOURNAL OF FLUID MECHANICS 448: 243-278 (2001). o van der Hoef M.A., Annaland M.V., Kuipers J.A.M. Computational fluid dynamics for dense gas-solid fluidized beds: a multi-scale modeling strategy. CHEMICAL ENGINEERING SCIENCE 59 (22-23): 5157-5165 (2004). o van der Sman R.G.M. Solving the vent hole design problem for seed potato packagings, with the Lattice Boltzmann scheme. INTERNATIONAL JOURNAL OF COMPUTATIONAL FLUID DYNAMICS 11 (3-4): 237-248 (1999). o VanderSman R.G.M. Lattice-Boltzmann scheme for natural convection in porous media INTERNATIONAL JOURNAL OF MODERN PHYSICS C 8 (4): 879-888 (1997) o van der Sman R.G.M. Lattice Boltzmann scheme for natural convection on square and rectangular grids. in revision Phys. Rev. E (2006). 